\title{
A Humean Theory of Moral Intuition ${ }^{1}$
}

\author{
Antti Kauppinen \\ Trinity College Dublin and University of Jyväskylä
}

Ask a man why he uses exercise; he will answer, because he desires to keep his health. If you then enquire, why he desires health ... he may ... reply, that it is necessary for the exercise of his calling. If you ask, why he is anxious on that head, he will answer, because he desires to get money. If you demand Why? It is the instrument of pleasure, says he. And beyond this it is an absurdity to ask for a reason. It is impossible there can be a progress in infinitum; and that one thing can always be a reason why another is desired. Something must be desirable on its own account, and because of its immediate accord or agreement with human sentiment and affection. (Hume [1751] 1948, 268-269)

As Hume notes in this famous passage, chains of justification come to an end in ethics just as they do elsewhere. At some point, the bedrock is reached, and there is nothing further to say. If someone still disagrees, we can only try to present the case in a different light and hope for persuasion, or point to fit with other things that we believe. It is often said that a proposition that does not require further inferential justification, such as It is wrong to harm an innocent child, is the content of an intuition. It is the distinctive claim of sentimentalist accounts like Hume's that moral intuitions are constituted by an emotional response rather than some purely intellectual insight. In this paper, I will develop a systematic sentimentalist account of moral intuition that aims to explain the commonalities and differences between moral and other intuitions.

The word 'intuition' is used for many different phenomena. I propose to identify intuitions in the sense at issue by their putative justificatory role in philosophical practice: intuitions are responses that are putatively either foundational justifiers for philosophically

\footnotetext{
${ }^{1}$ This paper was much improved by exceptionally insightful feedback from an editor and two referees for this journal. In addition, discussions of the material with Matt Bedke, John Bengson, Gunnar Björnsson, Lilian O’Brien, Jesse Prinz, Michael Ridge, Michael Smith, and Teemu Toppinen proved very useful, as did written comments from Michael Morris and Sabine Roeser. Work on this paper was supported by a grant from the Jenny and Antti Wihuri Foundation and The Netherlands Organisation for Scientific Research (NWO) research project "Good Pilots or False Guides? Emotions and the Formation of Moral Judgment."
} 
relevant non-empirical belief (so that someone who has the intuition that $p$ has defeasible justification to believe that $p$ without having to be able to infer it from a further proposition) or quasi-foundational justifiers for philosophically relevant non-empirical belief (so that someone who has the intuition that $p$ is entitled to treat $p$ as an initially credible starting point in a process of seeking reflective equilibrium without having to be able to infer it from a further proposition). Call this the intuition-role.

The question is: what, if any, kind of psychological states play the intuition-role in ethics, and why? The Humean claim, as I said, is that these states are a subset of emotional responses. To make the case for it, we need to do two things: to examine in some detail what intuitions in general and moral intuitions in particular are like, and then show that at least some emotions fit the latter description. There is much dispute about the nature of philosophical intuitions in general, but as I will argue below, there is much to be said in favour of the recently popular quasi-perceptualist view that they are quasi-perceptual appearances or seemings. Such appearances are spontaneous and compelling propositionally contentful experiences that result from merely thinking about a proposition or a set of propositions. In the absence of a sufficient reason to doubt things are the way they seem, they can justify belief without further inferential support.

Moral intuitions, too, have these features. But once we isolate them carefully, we can see that moral intuitions can have a special phenomenological and functional character. What I will argue is that both the shared and the distinctive features of substantive moral intuitions are best explained by the hypothesis that they are constituted by emotions that manifest moral sentiments. As Hume argued, moral justification bottoms out in such responses. But he failed to account for how these responses justify belief, since he did not properly appreciate their contentfulness. I 
defend an account of the phenomenal intentionality of moral emotions that allows us to see how they can justify belief in just the same way and to the same extent as seemings or appearances in general do. In effect, my goal in this paper is to marry a quasi-perceptualist account of moral intuition with a quasi-perceptualist account of moral emotion. The resulting epistemic sentimentalism contrasts traditional intellectual intuitionist views, which must carry the explanatory burden of accounting for how mere understanding can provide us with knowledge of non-analytic moral truths. ${ }^{2}$ It also contrasts with skeptical and deflationary views, on which what are called intuitions have no special character or justificatory status. If my defense is successful, our common practice of appealing to intuitions as fundamental sources of evidence of moral facts is justified, even if not for the commonly accepted reasons.

\section{What Intuitions Are: Quasi-Perceptual Appearances}

The nature of intuitions in general is a hotly disputed topic in the philosophy of philosophy. The traditional view is that intuitions are, roughly, beliefs or attractions to assent to propositions that result from merely adequately understanding the proposition (see e.g. Audi 2004; Sosa 2007). Some now hold a deflationary view according to which philosophical intuitions about hypothetical cases are simply judgments or conscious inclinations to believe that result from exercising ordinary capacities of counterfactual thinking, and consequently lack any special epistemic status (Williamson 2007). Of late, both of these views have been forcefully challenged by proponents of quasi-perceptualist accounts of intuition. Since I will be arguing in favour of a kind of quasi-perceptualist account of moral intuition in the next section, I will begin by examining some arguments in favour of this type of view in general. It will be a point of some

\footnotetext{
${ }^{2}$ I will be assuming that there are moral truths and facts about which we can form ordinary descriptive beliefs. Epistemic sentimentalism does not entail non-cognitivism.
} 
importance that we often use the term 'intuitive' for the broader subclass of propositions that we are immediately inclined to accept without conscious reasoning, for example because of association or quick unconscious inference. When thinking about intuitions, we should bear in mind that not everything that is intuitive is the content of an intuition.

The starting point for a quasi-perceptualist account is that propositions like the following appear true to me when I simply attend to them carefully, without reasoning from any beliefs I have or reliance on perception or memory:

(1) Nothing can be both blue and yellow all over.

(2) Necessarily, if someone knows that $p, p$.

(3) Unwanted pain is bad for me.

(4) There is a strong moral reason to refrain from torturing anyone.

(5) It is morally wrong to push an unsuspecting man off a footbridge to his death in order to stop a trolley that would otherwise hit and kill five other people.

(6) If $\mathrm{X}$ is better than $\mathrm{Y}$ and $\mathrm{Y}$ is better than $\mathrm{Z}, \mathrm{X}$ is better than $\mathrm{Z}$.

What is it for a proposition to appear or seem true to one? Consider the parallel with perception. The case of known perceptual illusions makes it very plausible that there is a gap between appearance and belief. Take Adelson's checker-shadow illusion. ${ }^{3}$ When we look at the image on the left, the square marked with B appears to be of a brighter shade of grey than the square marked with A. Yet the two squares are in fact of the exact same shade, as can be easily seen with the addition of two bars of the same shade, as on the image on the right:

\footnotetext{
${ }^{3}$ See http://web.mit.edu/persci/people/adelson/checkershadow_illusion.html.
} 

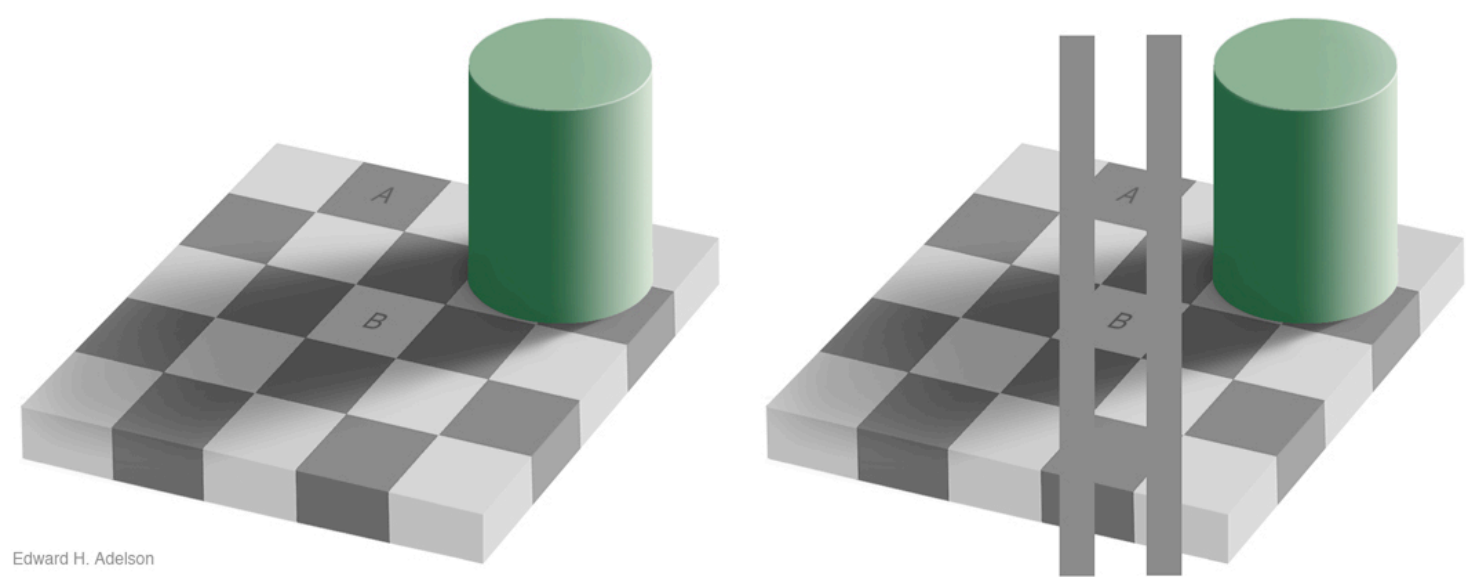

The visual appearance is psychologically independent of the belief - even after you have looked at the image on the right, if you focus just on the image on the left, the squares appear to be of a different colour. The appearance is thus non-doxastic. ${ }^{4}$ It is also spontaneous in that it's not under voluntary control or the outcome of inference or reasoning. It is not only recalcitrant, but also primitively compelling - by itself, it attracts you to believe that the A square is darker, because the experience seems to present to you the way things are. Indeed, it arguably not only attracts you to believe, but in itself provides prima facie justification for the belief. Were you not aware of the illusion, you might be justified in forming the belief. (Your awareness of the illusion is an undercutting defeater for the justification.)

Quasi-perceptualist views of intuition argue that intuitions form a subclass of appearances with similarities to and differences from perceptual appearances. ${ }^{5}$ They are, in short, quasiperceptual appearances. Like perceptual appearances, they are non-doxastic, spontaneous, and

\footnotetext{
${ }^{4}$ As Kathrin Glüer (2009) has pointed out, this argument for non-doxastic experiential content relies on the assumption that the content of the perception is the same as the content of the perceptual belief. She notes that if the appearance consists in a belief about what things look like, there is no puzzle: I can simultaneously (rationally) believe that the squares look to be of different colour and that they are of the same colour. As Glüer acknowledges, this requires denying that perception provides access to non-phenomenal properties, such as redness as opposed to looking red. For me, this suffices to motivate adopting the non-doxastic approach to experience, other things being equal. I thank a referee for this journal for calling this work to my attention.

${ }^{5}$ See e.g. Bealer (1998); Bengson (2010); Chudnoff (2011a); Huemer (2005); Koksvik (2011).
} 
primitively compelling. What makes an appearance quasi-perceptual is that it is not based on sensory or introspective sources either directly or indirectly (via memory), but on merely thinking about a proposition. Here is Michael Huemer's definition:

An intuition that $p$ is a state of its seeming to one that $p$ that is not dependent on inference from other beliefs and that results from thinking about $p$, as opposed to perceiving, remembering, or introspecting. (Huemer 2005, 102)

Note that this definition leaves it open just what constitutes thinking about $p$ and what kind of state intuition is. That is why I can agree with Huemer's definition, though I will reject his intellectualism.

Why should we think that intuitions are appearances rather than beliefs? A powerful reason is that we can have an intuition that $p$ without believing that $p$. For example, many have the intuition that the Naïve Comprehension Axiom is true, even though they know it is false (Bealer 1998). As Ole Koksvik points out, it is also important that if someone intuits that $p$ and believes that not- $p$, she's not rationally criticisable in the same way as someone who believes that $p$ and believes that not- $p$ (Koksvik 2011, 45). If intuition entailed belief, this wouldn't be true. This is another parallel with perceptual experience - you're not irrational if it still seems to you that A and B are not the same colour when looking at the image on the left.

Why should we think that intuitions are appearances rather than simply dispositions to believe or perhaps attractions to assent to a proposition on the basis of merely understanding it? (Williamson 2007; Sosa 2007) According to quasi-perceptualists, an intuition is a conscious experience, perhaps of a special kind, that one can have without being inclined to believe its content. One reason to think so is that intuitions have a phenomenal character with some commonalities with perception. In both cases, we seem to be directly presented with what's out there independently of us. In contrast to mere belief, it is as if we reach into the things themselves 
when we have the experience. This accounts for what I have called the compelling character of intuition. Think of the contrast between your belief that Rome is the capital of Italy and your intuition that nothing can be both blue and green all over. You may be quite convinced of the former, but not in the same way as of the latter. The difference may be even more evident when we compare the experiences of arriving at an empirical belief and arriving at the intuition that modus ponens is necessarily truth-preserving after considering some possible cases (focus on the “Eureka!" moment).

Some quasi-perceptualists, such as George Bealer (1998), argue that an intuition is a mental episode that is sui generis and irreducible. But Elijah Chudnoff (2011b) points out that intuitions can be irreducible while being constituted by other psychological states. The statue, most agree, is not identical with the lump of clay, even if the two are co-located and one constitutes the other. On Chudnoff's account, an intuition experience is like a melody experience: it is constituted by a collection of simpler thoughts that are suitably structured or organized so as to give rise to a new experience $(2011 b, 646-648)$. One benefit of this approach is that it helps respond to the standard dispositionalist objection, according to which introspection shows that intuitions lack a unified phenomenal character (e.g. Williamson 2007, 217). Chudnoff notes that if intuitions are constituted by other psychological states, it is not implausible to say that dispositionalists fail at introspection, because they are looking for the wrong kind of thing. He also points out that the presentational character of intuitions can be elusive and difficult to describe, because other experiences, such as the experience of imagining a scenario, can crowd out attention to the character of the intuition itself $(2011 \mathrm{~b}, 642)$.

Assuming that quasi-perceptual appearances share the epistemically relevant features of perceptual appearances (see Section 4), it is plausible that they play the intuition-role of being a 
foundational or quasi-foundational justifier for philosophically relevant non-empirical belief. Two points about this quasi-perceptualist view of intuition are particularly important. First, quasiperceptual appearances are not by definition the result of merely understanding the proposition in question. (They might be, but further argument is required.) Second, nothing said above rules out that different kinds of psychological state constitute intuitions about different subject matters, as long as they fit the description of being non-sensory, non-doxastic, spontaneous, primitively compelling, and putatively non-inferentially justifying. I will not hazard any kind of claim about modal or conceptual intuitions here. What I will be arguing for is simply that substantive moral intuitions are constituted by certain characteristically emotional experiences, and are in that respect unlike other intuitions.

\section{What Moral Intuitions Are: Emotional Manifestations of Moral Sentiments}

On the quasi-perceptualist view, intuitions are non-doxastic, spontaneous, compelling, and putatively non-inferentially justificatory experiences. In this section, I will argue that while moral intuitions share these features, they can also have distinctive characteristics that are best explained by their being constituted by a particular kind of emotional response.

\subsection{The Difference Between Moral and Other Intuitions}

Moral intuitions, such as (4) and (5) above, are in many ways similar to other intuitions, such as

(1)-(3). It can strike one that there is a strong moral reason against torture without any inference from what one believes, or regardless of what one wants. Indeed, torture may seem wrong to a utilitarian, who believes it to be justified in suitable circumstances. The seeming is thus plausibly non-doxastic and spontaneous. It is also compelling: when torture seems wrong, we do not 
experience a brute inclination to believe that it is; rather, the seeming makes the belief at least subjectively appropriate. The experience seems to present the very wrongness of torture to us without the need for inference from something more basic. (That is why the frustrated cry of "Can't you see it!" is so tempting when someone disagrees even after granting the facts about pain, humiliation, and such.) On the face of it, too, the seeming is epistemically relevant. At least, when we have it, we take ourselves to have some justification for believing in the content.

Yet there also important differences between moral and other intuitions. The first striking difference is phenomenological. Moral intuitions can and often do have a distinctive and diverse phenomenology. On the first point, compare the intuition that modus ponens is necessarily truthpreserving with the intuition that torturing the innocent is wrong. In both cases, the appearance carries a sense of conviction and acquaintance with the truth - it is an experience in which the very facts seem to be manifest to us. As often happens, the exact phenomenological character of the experience resists verbal description, but I believe that at least in some contexts, moral intuitions are gripping in a different way. I came to have the intuition that torture is morally wrong when I came upon descriptions of it in Holocaust literature as a teenager. The experience in which this truth was manifest to me was powerful in a way that coming to intuit the validity of inference or necessity of belief for knowledge simply is not. Strong moral intuitions may even have physiological manifestations - fists tensing, heart speeding up. (I'll return to less dramatic cases below.) On the diversity point, note that the character of the torture intuition may not be the same as that of the intuition that you have done something wrong in paying for sex, for example. Again, it is hard to put this in precise terms, but it seems that the dimensions of variation in phenomenal character are different in the case of moral intuitions than in the case of logical or epistemic intuitions. It is not just the strength of conviction or clarity that varies, but the timbre 
and tone of the experience as well.

The second main difference from other kinds of intuition is functional. Moral appearances can be intrinsically motivating. This is again clearest when the way things seem to you is contrary to your beliefs. Consider walking past a dirty, pathetic beggar on the street on a rainy day. I am fairly convinced by the arguments that we should not give money to street beggars, because it provides people with wrong kinds of incentive and will not in fact benefit them. Indeed, there is a high risk of making the beggar worse off. Yet when I look at the weather-worn face and hear the polite request, it sometimes seems to me that I really ought to give this time. I am not only inclined to believe that I should give this time, but also feel the motivational pull. Sometimes such seeming can result in action even if I do not change my belief. I believe this is a good way to understand some cases of inverse akrasia, such as Huckleberry Finn's famous refusal to report the escaped slave Jim in spite of his belief: though he believed he ought to do it, it just did not seem right to him, so he lied instead.

Elsewhere (Kauppinen forthcoming a), I defend the view that moral beliefs themselves are not essentially motivating or linked to motivation, while moral intuitions do intrinsically motivate. This helps explain why the debate between moral internalism and externalism seems irresolvable - in effect, there are two kinds of moral thoughts, and internalism is true of one kind while externalism is true of the other. ${ }^{6}$ On this interpretation, psychopaths and other amoralists may be able to make genuine moral judgments without being motivated, since those judgments are just ordinary beliefs. But the wrongness of doing certain things is not experientially manifest

\footnotetext{
${ }^{6}$ My view thus belongs to the category of moral thought pluralism. Linda Zagzebski (2003) distinction between ground level (or Level 1) moral judgment (which is an emotional state with necessarily connected cognitive and affective aspects that attributes a thick affective concept to something) and Level 2 and 3 moral judgments ('indirect' beliefs that something has an evaluative property and beliefs involving thin evaluative concepts) is an earlier instance of this type of view. However, I believe intuitions are better construed as appearances rather than judgments of any level, and my views of both emotion and justification are different from Zagzebski's.
} 
to them by way of intuition, at least not in the distinctively moral way.

So, like other intuitions, moral intuitions are non-doxastic, spontaneous, primitively compelling, potentially non-inferentially justifying experiences. Unlike other intuitions, they are often also phenomenologically rich and diverse, and intrinsically motivational. What account of their nature best explains why they have these core features? Clearly, they are neither just phenomenology-free inclinations to believe nor beliefs. Are they, then, intellectual seemings of the sort that intellectual intuitionists (e.g. Huemer 2005) take them to be? On the face of it, intellectual intuitionist models offer a promising explanation of the commonalities between moral and other intuitions. But what about the distinctive features of moral intuitions, their phenomenology and motivational role?

Here, the intellectualist models fare much worse, precisely because according to them moral intuitions are just the same sort of state as other intuitions, the only difference being in content. Assuming that phenomenal character and motivational role are a matter of attitude rather than content - after all, that is where the difference between desiring that $p$ and believing that $p$ lies - the intellectual seeming view leaves it puzzling why moral intuitions have distinctive features. According to the Humean Theory of Motivation, purely cognitive states (states with only a mind-to-world direction of fit) cannot move us to act, whatever their content. Assuming that this is true, moral intuitions cannot be purely cognitive states, if they are even potentially motivating. Yet they must also have a mind-to-world direction of fit, since they present things as being in a certain way either accurately or inaccurately, like perceptual experiences. So they cannot be purely non-cognitive states either. The remaining alternative is that they are constituted by states that have both directions of fit. Many contemporary theories of emotion suggest that emotions have this unique feature. It is thus worth exploring the hypothesis that moral intuitions 
are emotional in nature, more precisely emotional manifestations of moral sentiments. ${ }^{7}$

\subsection{Moral Sentiments}

What are moral sentiments? As I will use the term, sentiments in general are dispositional states or stances that manifest themselves in a variety of different ways (cf. Prinz 2007). The non-moral sentiment of love can be manifest in joy when its target fares well, in sadness when she fares badly, in desire to be in her company, and even in a tendency to believe good rather than bad things about her. Similarly, the sentiment of moral disapprobation may manifest itself in anger at the agent, in extra compassion for the victim, in desire to avoid doing the sort of thing the agent did, in guilt if one nevertheless does the same, and in attraction to believe the action is wrong.

What makes some sentiments moral? For Humean intuitionists, it cannot be that they result from or involve moral belief, since that would rule out intuitions foundationally justifying belief. Briefly, moral sentiments are best understood as comprised of two elements: a disposition to praise or blame someone on account of an attitude, action, or act-type, and an authorityindependent normative expectation that everyone share the disposition to praise or blame. Praise and blame take many forms, but at least some of them involve reactive emotions such as admiration, gratitude, anger, and resentment. In themselves, these reactions are not moral. Contrast two traffic cases. I am an impatient person, and resent people who drive under the speed limit in good weather conditions. I do not, however, normatively expect my resentment (a personal rather than moral reactive attitude) to be shared by everyone else. But if someone cuts in

\footnotetext{
${ }^{7}$ This may not sound like a particularly striking claim, as it is not unusual to talk about moral intuitions and emotional responses in the same breath (see e.g. Haidt 2001, Roeser 2011). But earlier efforts have not systematically considered the nature of intuitions in general, nor satisfactorily accounted for their epistemic significance. Of earlier views, Graham Oddie's (2005) view does have important similarities with mine. But it concerns desires as experiences of value, not sentimental manifestations as moral intuitions, and he relies on a different view of justification in general. Sabine Döring (2007) also defends a similar view, but for her emotions are "affective perceptions" rather than intuitions. In my view, perception requires a causal relation between instantiation of the perceived property and the experience. That is missing in the case of emotional appearances of value.
} 
front of me in traffic, my reaction is different. The difference lies in the normative expectation, which is itself a disposition to blame those who lack the first-order blaming response, praise those who do, and so on (for this notion of emotional ascent, see Blackburn 1998). This normative expectation is not contingent on others expecting me to have it, unlike in the case of social norms. Nor does it presuppose or involve any normative judgment or belief - we can have the relevant sentiments independently of judgment. The normative expectation is activated when the higher-order sentiments manifest themselves in a set of emotional responses, which then motivate sanctioning behaviour.

The second mark of moral sentiments is that they are canonically felt from what Hume called the 'common point of view', an intersubjectively shareable perspective (see e.g. Cohon 1997). It is possible, to be sure, to feel moral disapprobation without taking up the common point of view, for example as a result of being frustrated by slow driving. But there is surely something odd about normatively expecting others to share such reactions. It is only by chance that they might do so. Further, it is plausibly the practical point of moral thinking is to reduce interpersonal conflict and to avoid, for everyone's long-term benefit, collectively self-defeating pursuit of selfinterest. This goal can only be reliably met if we regulate our approbation and disapprobation by reference to a perspective that can be shared by those who fail to share our interests and tastes. The details of the common point of view do not matter here; the point is simply that some sentiments merit being called 'canonical', since their aetiology makes them robustly shareable, at least among those willing to live under the terms they propose for others.

\subsection{Moral Emotions as Quasi-Perceptual Appearances}

My claim is that the best explanation of the core features of moral intuitions is that they are 
constituted by emotional manifestations of moral sentiments - for short, moral emotions (to use the term in a somewhat stipulative sense). To substantiate this, I will next defend a view of moral emotions that shows how they are fit for the moral intuition-role.

First, and most importantly, moral intuitions are non-doxastic presentations of moral facts. At a minimum, this means they have propositional content, and attract us to assent to it, but do not involve commitment. Is this true of moral emotions? Hume himself famously held that a passion is "an original existence" which "contains not any representative quality, which renders it a copy of any other existence" ([1739-40] 1978,415). The significance of this passage is disputed among Hume scholars, and it may not fit well with some of the other things he says about the passions. In any case, historical interpretation is not my concern here - it does not really matter how authentically Humean my view is. What matters is that emotions do after all have intentional content with a mind-to-world direction of fit, as it is now common to acknowledge. Theories of emotion often distinguish between two kinds of intentional content. First, (most) emotions have a target, something they are directed towards: I am afraid of a bear, I am delighted by the news. Second, and more importantly for my purposes, (most) emotions have a formal object, the feature they present their target as having. In fearing, for example, the target appears or is construed as dangerous. To say this is not just to say that fear is appropriate only if the target is dangerous, or that it in itself inclines us to believe that its target is dangerous. It is rather to offer an explanation of why it is only appropriate if the target is dangerous. It is because otherwise its content will not match the way things are.

A simple explanation of the intentionality of emotion is to say that the emotion is either wholly or in part constituted by a belief to the effect that the target has the feature that is the formal object. Recalcitrant emotions offer a good reason to reject this view (Roberts 2003, 
D'Arms and Jacobson 2003). I can fear getting on a plane even if I believe it is not dangerous. But it is not just recalcitrance in the face of belief that is decisive - we do, after all, sometimes have contradictory beliefs. An argument inspired by Koksvik's (2011) case against belief theories of intuition is more powerful. It is simply that fearing $\mathrm{X}$ while believing that $\mathrm{X}$ is not dangerous is not irrational in the same way as holding contradictory beliefs. Unlike in the case of known perceptual illusion, however, there is something off about having such combination of attitudes towards X. Why? One explanation is that although it is not strictly incoherent to feel the attraction to believe that $p$ while believing not- $p$ and, such a psychology is fragmented and fragile in a rationally relevant way. You are one nod away from believing a contradiction. In the case of perception, the seeming that $p$ is strongly cognitively impenetrable, which exculpates the subject. I conjecture that we regard the person with recalcitrant emotion as somewhat rationally criticizable because we take emotions to be more permeable to rational influence, even if only indirectly. (In some cases, to be sure, the rational way to achieve unification is to change the belief.) Emotions also contrast with perceptions in that they often causally depend on rationally assessable beliefs about the attributes of the target, and may thus be indirectly rationally assessable. ${ }^{8}$ Nevertheless, being torn between emotion and belief about formal object is not the same problem as both believing that $p$ and believing that not- $p$. This suffices to show that emotions do not entail or contain beliefs or judgments about the target having the property that is the formal object of the emotion. It is more plausible that they are or involve non-committal appearances that the target has the property. Call this a quasi-perceptualist theory of emotion.

What exactly is the relation between the emotion and the appearance? According to addon views, the appearance is a detachable component of the emotion, so that the feeling or

\footnotetext{
${ }^{8}$ Since I argue that moral intuitions are constituted by emotions, I am committed to moral intuitions, too, being rationally assessable in this indirect way, and being more cognitively penetrable than perceptual appearances. As a referee for this journal pointed out, this may be an important point of contrast with other intuitions.
} 
phenomenal character of the emotion is irrelevant to its intentional content. On this kind of view, an intellectual intuitionist could grant that emotions involve intuitions, but rather than the emotion constituting an intuition, the intuition in part constitutes the emotion. ${ }^{9}$ Fortunately for the Humean, there is independent reason to be skeptical of views according to which the feeling aspect of emotion is just an add-on to its intentional content. As Peter Goldie in particular has argued, the experiential aspect of emotion is not just some brute or bodily sensation lacking intentionality, but is rather a matter of feeling towards the target "as being a particular way or as having certain properties or features" (Goldie 2000, 58). Consider Uriah Kriegel's persuasive example of losing a grandfather. He observes that "It is not as though my grief consisted in bodily sensations accompanied by a bloodless, unfelt, unconscious, non-experienced appreciation of loss. ... On the contrary, the loss itself showed up in consciousness - it was 'experientially encoded', if you will." (Kriegel forthcoming). It is the very experienced feeling towards the death of a loved one that presents it as a loss, not some separate component of the emotion. Indeed, without the feeling, one's representation of the death as a loss would be rather like a colour-blind person's belief that something is red. ${ }^{10}$ It is in part to emphasize this difference that I say an emotion presents rather than merely represents the target as having the formal object.

Recent work in cognitive phenomenology points in the same direction. Terence Horgan and John Tienson (2002) argue that paradigmatically phenomenal mental states have "intentional content that is inseparable from their phenomenal character" (521), content that they have in virtue of their phenomenal character. The core idea is that part of what it is like to have an experience of a red object, for example, is to experience the colour as belonging to an external,

\footnotetext{
${ }^{9}$ I thank an editor and a referee for this journal for pressing this line of objection.

${ }^{10}$ Goldie contends that this is a difference in content: "[T]here could not be some other psychological episode, say belief or thinking of, with the same content but with no feeling" (Goldie 2000,72). If this is the case, there is even stronger reason to reject the add-on thesis: a detachable intuition component does not suffice to account for the intentional content of the emotion.
} 
persisting object distinct from one's flow of experience itself. The experience is directed outwards, as it were, in virtue of its phenomenal character, which suffices to endow it with conditions of accuracy. It is contentious how fundamental and important phenomenal intentionality is (see the papers in Kriegel (ed.) 2013), but for my purposes, the relatively broadly accepted thesis that the what-it's-like of experience can suffice to determine its intentional content is enough. It provides a broader framework supporting the thesis that the intentionality of emotion is inseparable from the way it feels.

How does a moral emotion present its target as in virtue of the way it feels? Much recent work in this area treats the formal object of any emotion as an evaluative property (e.g. Tappolet 2011). Whether this is true or not, not all evaluation is moral. Emotions may present their target as attractive or aversive in a pre-moral sense. Think of anger, for example. Psychologists often describe the formal object of danger as offense to self or those one cares about. The feelings involved in anger construe the target as offensive - part of what it is like to feel angry is to experience the target in that way. But such thoughts are not yet moral. As argued above, moral sentiments derive from personal, non-moral counterparts with the addition of an authorityindependent normative expectation of being shared. If you are angry and you actively normatively expect others to share a blaming reaction, it appears to you that anger, and guilt on part of the agent, is called for or a fitting response to an object that is somehow objectively offensive. (We sometimes call anger of this kind indignation or righteous anger.) Recall Chudnoff's comparison to experiencing a melody: it is the whole of interrelated emotional responses that constitutes the experience of wrongness (or fittingness of blame). That experience may come in different varieties: delight at someone's punishment for torture may be an element of an experience that presents torture as being wrong. 
My claim is that it is the very phenomenal character of the complex emotional experiences of the sort I have described (such as a blame-feeling together with a higher-order blame-feeling towards those who fail to share it) that presents the target in the right kind of negative light. It is not as if we have some brute, directionless bad feeling or sensation combined with either belief or intuition that the target did something wrong. It is rather a part of what it is like to have the feeling that its target appears to call for a negative response. The intellectual intuitionist challenge neglects this feeling towards the target as the source of the emotion's intentionality, and thereby commits itself to what is arguably a mistaken theory of emotion in general.

Since the feeling is a basic way of being conscious of the target as objectively offensive, it has content that can either fit the way things are or fail to do so. Just as in the perceptual case, there is room for debate about whether the content is conceptual or non-conceptual. Since the emotional response need not involve explicitly thinking that the action is wrong, and might conceivably be had by someone who lacked the concept, it might be best to label it preconceptual. But I take it that it is sufficiently closely related to the proposition that the action is wrong to potentially rationalize the belief. Again, there is a parallel to the perceptual case, where the content of the perception and the content of the belief might not be an exact match, but nevertheless stand in a rationalizing relation. The presence of the authority-independent normative expectation also helps explain the compelling quality of the intuitive experience. Since I expect the response from everyone, I regard it as demanded by the object itself, not as some quirk of mine.

If what I have argued so far is correct, constitution by moral emotions explains those core features of moral intuitions that they share with other intuitions: spontaneity, contentfulness, and 
compellingness. How about the phenomenological and motivational character of intuitions? On this point, Adam Smith rightly emphasized that we have a plurality of sentiments of approbation and disapprobation: "Our horror of cruelty has no sort of resemblance to our contempt for meanspiritedness." (Smith [1759-90] 1976, 325) According to the Smithian model, the intuition that someone has acted unjustly is constituted in part by a (manifestation of a) negative reactive attitude such as resentment, while the intuition that someone has done something morally depraved might involve a tinge of disgust. The intuition that someone has done something morally admirable might be constituted by a sentiment of approbation toward admiring her.

These various moral emotions have a distinctive and diverse phenomenology that neatly matches the distinctive phenomenal character of moral intuitions. It is plausible that the phenomenal difference between the quasi-perceptual appearance that nothing can be both blue and yellow all over and the quasi-perceptual appearance that what was done at Abu Ghraib is wrong matches the difference between the phenomenological difference between, say, the inability to imagine anything both blue and yellow, on the one hand, and the indignation felt toward the people responsible for Abu Ghraib, on the other. Similarly, the motivational role of moral intuitions appears to coincide with the motivational role of emotions. Think again about Huck Finn on the raft, about to betray Jim's confidence to the slave-catchers, believing it the right thing to do. It is plausible that what moves him to lie is his acute discomfort at the thought of letting Jim down. It is not an accident that we can say "it felt wrong" just as well as "it seemed wrong”. And consider the diversity of motivating intuitions. Suppose you believe there is nothing wrong with visiting a prostitute and act accordingly, but nevertheless what you have done in paying for sex seems wrong to you, and motivates you to hide from the eyes of others and take another shower. Surely if the moral seeming is constituted by the shame you feel, its functional 
role is fully explained.

So, the hypothesis that moral intuitions are constituted by manifestations of sentiments explains both the ways in which they resemble and differ from other intuitions. It is hard to think of a more elegant and parsimonious explanation. There is no need to postulate a sui generis state. Consequently, we have good reason to think the sentimental constitution claim is true.

At this point, I want to emphasize that Humean intuitionism is very different from those affectivist views of intuition that identify them with unreflective gut reactions or flashes of approval or disapproval. Psychologists these days commonly distinguish between 'System 1' or ‘intuitive system' - briefly, psychological processes that are quick, automatic, effortless, consciously inaccessible, and often affective and products of evolved psychological modules and 'System 2' or the 'reasoning system', comprised of psychological processes that are conscious, slow, potentially rational, and controlled, and tax working memory. Many psychologists, such as Haidt (2001) and Kahneman (2011) use the term 'intuition' for any System 1 output. This includes beliefs that result from expectations based on experience or quick and dirty inferences. (It is intuitive that rainy summers increase the sales of holidays in the sun.) They are 'intuitive', but nevertheless not intuitions in the sense of quasi-perceptual appearances. So not all System 1 outputs are intuitions in the relevant sense. Insofar as psychologists and neuroscientists do not discriminate among quasi-perceptual appearances and other System 1 outputs, what they study may not be people's intuitions in the philosophical sense at all. Moreover, System 2 may be involved in generating intuitions. To get to the point at which intuition spontaneously comes, we may need to engage in active inquiry and reflection paradigmatic System 2 processes. This is particularly important for canonical, potentially epistemically significant moral intuitions. 
Finally, a Humean intuitionism naturally rejects the traditional view that moral intuitions are beliefs or attractions to assent to propositions that result from mere adequate understanding. Making the case against intellectual intuitionist views goes beyond the brief of this paper. Rather, my goal is to make the sentimentalist alternative plausible on its own terms. But I do want to note some obvious advantages. A Humean intuitionism has no need to make the case for the synthetic a priori. It does not need to postulate that mere understanding can reveal to us something that does not concern the relations among our own concepts. Nor does it have to explain how our thoughts can non-accidentally align with non-natural facts with which we have no causal commerce. To be sure, to note these challenges for intellectual intuitionists is not the same as to argue that they cannot be met (for such arguments, see Bedke 2009). Indeed, as I will suggest at the end, the two accounts of non-inferential moral justification are not even strictly incompatible. But the heavy explanatory burdens that classical intuitionism has to carry suffice to motivate the search for an alternative approach. Given that I have made an independent case for quasiperceptualism about intuitions and argued that certain emotions can play the intuition-role, it would be question-begging at this point to insist that an 'intuition' must be a priori.

\section{Three Objections to Humean Intuitionism}

\section{Objection 1: Dispassionate Moral Intuitions}

One standard objection is that it is possible to have a moral intuition while being completely unemotional. My response to this is twofold. First, we must in any case distinguish between what I'll call substantive and formal moral intuitions. Substantive intuitions concern the non-trivial extension of moral properties - which things are morally right or wrong, good or bad, where this is not true by definition. They thus concern issues about which normative theories (at least 
potentially) disagree. By contrast, formal intuitions are independent of these substantive views even a nihilist could agree to the transitivity intuition (6) above. On my view, formal intuitions with a moral subject matter are just the same kind of state as any other formal intuitions, such as "If $\mathrm{X}$ is bigger than $\mathrm{Y}$ and $\mathrm{Y}$ is bigger than $\mathrm{Z}, \mathrm{X}$ is bigger than $\mathrm{Z}$ " - what intuitions about this and (6) target is the comparative nature of the predicate in question, not its substantive content. So it is entirely unsurprising that they are of a different kind than substantive intuitions.

Second, sentiments in general manifest themselves in a variety of ways, some of which may be unemotional. The sentiment of liking chocolate ice cream may manifest itself in delight when one is eating some, but also in a lukewarm flash of preference or a cold inclination to stop by the freezer isle in the supermarket. Similarly, a moral sentiment of disapprobation may manifest itself in indignation when witnessing a beating, but also in what Hume famously called a 'calm passion' that has few salient phenomenal qualities. The latter will still present the action as wrong and so count as an intuition on my view. The same sentiment may also be manifest in the mere attraction to believe that the agent did something wrong. When such attraction derives from a sentiment that would, in some suitable counterfactual circumstance, give rise to a quasiperceptual appearance, it merits being called intuitive attraction. Some cases of putative unemotional intuitions are instances of intuitive attraction. Perhaps after reading about the Footbridge case 468 times, I no longer respond with even the calmest of passions. On my view, then, I no longer have the intuition that pushing the heavy man is wrong. But I may still be intuitively attracted to think so. ${ }^{11}$ Nor is this attraction unrelated to the intuition I used to have. To this extent, then, Humean intuitionism can accommodate unemotional substantive intuitions and intuitive attractions.

\footnotetext{
${ }^{11}$ This process bears some resemblance to what Zagzebski (2003) calls the 'thinning' of moral judgment (see note 4 above).
} 


\section{Objection 2: Accompaniment Instead of Constitution}

I have granted that intuitions about other subject matters are non-emotional quasi-perceptual appearances, and that moral appearances can be relatively dispassionate. So how can I rule out the alternative theory that moral intuitions are run-of-the-mill quasi-perceptual appearances that are only contingently accompanied by emotions?

I have a modest and a bold response to this worry. The modest response is to grant that substantive moral intuitions can be multiply realized, so that only some moral intuitions are constituted by moral emotions. But I have already made the case that moral emotions constitute quasi-perceptual appearances, and hence do not merely accompany intuitions. Even if there are also other kinds of moral intuitions, it is still an interesting and potentially controversial thesis that moral emotions, too, constitute intuitions, and can be sources of moral knowledge. This might be metaphysically untidy, but it would still give certain emotions a fundamental role in moral epistemology.

The bold response involves appeal to response-dependent metaphysics of moral properties. It seems to be the case that some emotions, such as fear, present response-independent properties, such as danger, while simultaneously disposing us to seek shelter (they have two directions of fit). I take it that danger can be understood in terms of objective risk of harm, without making reference to our reactions toward what is dangerous. If so, the state of affairs of S being dangerous can perhaps also be presented by a unidirectional mind-to-world state - it can seem to you that $\mathrm{S}$ is dangerous without your being afraid.

Other bidirectional states, such as disgust, present response-dependent properties, such as being disgusting. Here it is not the case that the same feature could be presented by some other 
state. We can of course believe that something is disgusting without being disgusted by it, but it will not be the case that it primitively appears as disgusting to us unless we are disgusted by it. The presence of a response-dependent property is directly manifest to us exclusively in our having the response (perhaps in the suitable conditions). Someone who is incapable of disgust will have to infer that something is disgusting, and hence will not be able to 'intuit' it. Similarly, nothing seems funny to someone who entirely lacks a sense of humour, although they may still believe, for example, that The Simpsons is amusing on the basis of testimony.

Suppose, then, that moral properties are response-dependent. For example, perhaps it is wrong to $\phi$ if and only if anyone successfully occupying the common point of view would endorse disapproving of $\phi$-ing, in the absence of sufficient excuse. This is one way to cash out the idea that something is wrong iff disapproval is merited or fitting. ${ }^{12}$ In that case, moral disapprobation will be relevantly like disgust or amusement. Just as it cannot appear to me that something is disgusting or funny without my being disgusted or amused, it cannot appear to me that something is wrong without my sentiment of disapprobation manifesting itself. To be sure, unless I approximately occupy the common point of view, the intuition is likely to mislead (see below), but it will still be constituted by the emotion. Someone who lacks the sentimental response will at best be able to infer the presence of moral properties, and will thus lack intuitive, non-inferential access. If this is the case, the emotional response does not merely accompany the intuition, but is both necessary and sufficient for it.

\section{Objection 3: Getting the Extension Wrong}

I have argued that intuitions are quasi-perceptual states that can non-inferentially justify non-

\footnotetext{
${ }^{12}$ See Kauppinen forthcoming $b$ for a more detailed defense.
} 
empirical belief, and that some object-directed emotions are quasi-perceptual states that are fit to play the intuition-role. But not all emotions, such as fear of a bear while camping, constitute intuitions. Indeed, introspection suggests that such emotions are altogether different from paradigmatic intuitions, such as the intuition that $\mathrm{XYZ}$ on Twin Earth is not water. So exactly how is fear of a bear like an intuition, and why is it nevertheless not one? ${ }^{13}$

My response to this challenge is twofold. First, it is central to my argument that quasiperceptual appearances can be constituted by many different kinds of states, which can be expected to differ phenomenally in many ways in spite of all presenting things as being in a certain way. Thus, it is not surprising if the commonalities between emotions and conceptual intuitions are salient only after reflection that involves abstracting away from some striking differences, and consequently easy to miss in introspection. ${ }^{14}$ Further, emotions like fear have less in common with paradigmatic intuitions than moral emotions do. Fear is much less compelling, since it is not accompanied by normative expectation. In this epistemically relevant respect, fear is phenomenally unlike indignation and Twin Earth intuitions. Second, while fear of a bear is a quasi-perception, it is not fit to play the intuition-role as I have defined it. I have said that only quasi-perceptions that are fit to provide justification for philosophically relevant and non-empirical beliefs are intuitions in the relevant sense. To avoid unnecessary controversy, I have not given a definition of philosophical relevance or non-empirical belief. Roughly, I have in mind beliefs whose truth bears on the acceptance of a philosophical view but could not be established by standard scientific inquiry. Assuming that beliefs about dangerousness are not of that kind, fear will not be fit to play the intuition-role, even though it has some weak justificatory

\footnotetext{
${ }^{13}$ This point was forcefully pressed by an editor for this journal.

${ }^{14}$ A referee suggested that the phenomenal character of a quasi-perception might be thought of as a determinable whose determinates include the characters of moral and other intuitions, among other things. If this intriguing idea turns out to be correct, there is no more reason to expect different quasi-perceptions to share a common phenomenal character than there is to expect looking red and looking yellow to do so.
} 
standing as a weakly compelling presentation. I acknowledge that this part of the response remains tentative in the absence of a worked-out metaphilosophical theory.

\section{How Moral Intuitions Justify}

I have argued that emotions that manifest moral sentiments constitute moral appearances - in having the emotion, something seems right or wrong or depraved or admirable. It is possible to accept this, but nevertheless deny that such appearances constitute moral intuitions on the grounds that intuitions are supposed to provide justification for moral belief, and emotional responses fail to do so. In this section, I will argue that emotional responses qua moral appearances do provide justification or credibility to belief, just as appearances in general do. I draw on an epistemological framework that is variously called epistemic liberalism (Bengson 2010; Koksvik 2011), phenomenal conservatism (Huemer 2001, 2005), or dogmatism (Pryor 2000):

\section{Epistemic Liberalism}

If it appears to subject $\mathrm{S}$ that $p, \mathrm{~S}$ has some justification for believing that $p$, unless $\mathrm{S}$ has sufficient reason to doubt the appearance.

This is a permissive account of (propositional) justification, but not maximally so. It requires neither that appearances are actually truth-conducive, nor that the subject has reason or warrant to think that they are. However, it does not say that if S merely believes that $p$, she has justification in the absence of reason to doubt, unlike some default entitlement views. Nor does it say that just any experience is sufficient for providing justification, only the appearance or seeming or presentation that $p$. Wishing or imagining that $p$ does not entitle you to believing it. Only compelling, spontaneous presentations, such as perceptual and quasi-perceptual appearances, have this status. The core argument for this type of epistemic approach is straightforward. Given 
that perception or intuition that $p$ presents $p$ to the subject as being the case and does so in a way that appears to make belief appropriate, "it seems unreasonable to criticize such a subject as doing something epistemically improper in subsequently coming to believe that $p$, absent reason to so believe" (Bengson 2010, 76). When you are walking in the woods and it seems to you, vividly and clearly, that there is a bear right there in front of you, and you have no reason to doubt your senses, surely you could not be faulted for giving some credibility to the notion that there is a bear in front of you. ${ }^{15}$ The argument could be extended to intuitive attractions we have no reason to question, though their justificatory force is surely weaker, as they lack the presentational aspect of appearances.

If what I have said about the quasi-perceptual character of moral emotions is right, the same goes for them, too. Suppose you have carried out your non-moral epistemic responsibilities in finding out the facts of a situation, say the incident between Dominique Strauss-Kahn and the hotel maid, and done your best to adopt the common point of view, including putting yourself in the shoes of all the parties and leaving aside your prior feelings towards them. Maybe you end up feeling outraged by Strauss-Kahn's behaviour, so that it spontaneously and compellingly appears as morally wrong to you. It would surely be unreasonable to criticize you for giving some initial credibility to the proposition that what he did was wrong.

So, insofar as it is granted that moral emotions are moral appearances, as I have been arguing in the previous sections, there is no reason to think that the general picture of justification I have just sketched fails to apply to them. That is, insofar as it emotionally appears to a subject that $p$, she is prima facie justified in believing that $p$, in the absence of a sufficient reason to doubt her appearances. Or more weakly: a sentimental intuition that $p$ provides initial credibility

\footnotetext{
${ }^{15}$ See Pryor 2000 and Huemer 2001 for further argument.
} 
to $p$, so that it merits consideration in a process of reflective equilibrium.

I do not deny that we $d o$ have sufficient reason to doubt many emotional appearances. Consider what kinds of things generally undercut the justificatory force of appearances. Walter Sinnott-Armstrong argues that inferential confirmation is needed when the believer is partial, when there is disagreement without independent reason to think one person is in a better epistemic position, when judgment is clouded by emotion, when circumstances are conducive to illusion, and when belief arises from an unreliable or disreputable source (Sinnott-Armstrong 2006, 343-346). Unless we adopt the common point of view when responding to a principle or scenario, many of these defeaters to non-inferential justification are present: the sentiments are likely to be partial, to clash with each other with no independent reason to prefer any, and to be clouded by morally irrelevant feelings like disliking someone who is different from us. Our emotions are also easily influenced by the way that a case is presented to us. Presentational influences such as framing effects are among what Sinnott-Armstrong regards as circumstances conducive to illusion. So there are good reasons to doubt undisciplined emotional appearances.

Suppose, on the other hand, that you succeed in adopting the common point of view before responding emotionally. By definition, then, your praise and blame are not influenced your self-interest, personal ideals or idiosyncrasies, or the similarity or vicinity of the agent or patient to you. Your factual beliefs are also true. Since this perspective is essentially intersubjectively shareable, anyone who is your epistemic peer will agree. The influence of prior passions and mood is also neutralized. So at least these standard defeaters for non-inferential justification are absent. Some circumstances may admittedly still be conducive to illusion, but they will be special cases. This is no more troubling for moral justification than it is for perceptual justification.

It is thus no part of my project to deny that emotions and underlying sentiments can be 
fickle, partial, ill-informed, influence by mood, hurry, prejudice, and circumstance. Not all intuitions are created equal. Since moral appearances are constituted by emotions, which are not as cognitively impenetrable as perceptual appearances, they are more susceptible to certain kinds of distorting influence than perceptions or other intuitions. That is why we often need to make a conscious effort to take up the common point of view, which involves transcending such influences. It is a vital part of moral education to learn to step back from initial reactions and consider the facts relatively coolly. All I claim is that such a step does not involve transcending emotional sensibility altogether, and that this is no bar to making use of the standard story of intuitive justification.

\section{Conclusion: Justifying Philosophical Practice}

It is not common for practicing moral philosophers to identify the spontaneous responses they rely on as any kind of manifestations of sentiments. Why, if what I have argued for is true? I suspect that many, quite rightly, eschew any reflection on the nature of their responses. Those who do reflect may find moral appearances so compelling that they are reluctant to believe they

are emotional, given the reputation for caprice that emotions have acquired. Further, when moral passions are calm, they lack some distinctive features of paradigmatic emotions. And finally, the sentimental origins of intuitive attractions to believe are not transparent. So it is not so surprising that many tend to think of intuitions as non-emotional.

Yet occasionally philosophers do observe the sentimentality of intuitions when reflecting on their practice. Here is a passage on approaching assisted suicide in a recent interview with Thomas Scanlon:

Now, when I think about such cases ... I almost always think about myself in the position of the person who wants to die. I'm on the battlefield. I'm in pain. I'm about to die. The 
enemy troops are approaching. They have a terrible reputation for how they treat wounded prisoners, and so I plead with the medic to give me a shot of morphine. And if he says: "Sorry, God forbids it," or something, I'd be pretty angry. So I get similarly indignant about the state trying to tell somebody that they couldn't help me die. I feel very solid about these things. ${ }^{16}$

I think proceeding as Scanlon describes is both epistemically responsible and more common than usually acknowledged. In serious ethical reflection, we contemplate a case, trying to untangle what is at stake for different individuals, what causal relationships obtain, and perhaps what the alternative scenarios are, and then imaginatively project ourselves into different positions before responding emotionally, often with a calm passion. Nevertheless, balancing beliefs based on such responses and thinking of new cases to test the implications of tentative principles remains a paradigmatic rational and reflective process. As ever, we rely on intuition only when reason gives out.

Finally, if what I characterized as a modest version of the view is true, only some of our intuitions are sentimental, while other intuitions are intellectual. This is untidy, but not inconsistent: quasi-perceptual appearances in any case come in different varieties and have different sources. If there is a systematic split, I would suspect that intuitions about general principles are the best candidates to be the object of intellectual intuition, and intuitions about particular cases of sentimental intuition. This is not a novel idea - utilitarians like Peter Singer have proposed something similar (Singer 2005). But they have then advocated rejecting the sentimental intuitions. What I have argued for is instead that emotional appearances of a particular kind confer the same kind of initial credibility to moral propositions as appearances in general do, and for the same reasons.

\footnotetext{
${ }^{16}$ Interview with Yascha Mounk for The Utopian, July 7, 2012. Quote on http://www.the-utopian.org/T.M.-Scanlon-Interview-4 (accessed December 3, 2012).
} 


\section{References}

Audi, Robert. 2004. The Good in the Right. Princeton, NJ: Princeton University Press.

Bealer, George. 1998. "Intuitions and the Autonomy of Philosophy." In Rethinking Intuition, edited by Michael DePaul and William Ramsey, 201-240. Lanham, MD: Rowman \& Littlefield.

Bedke, Matt. 2009. "Intuitive Non-Naturalism Meets Cosmic Coincidence." Pacific Philosophical Quarterly 90 (2): 188-209.

Bengson, John. 2010. “The Intellectual Given.” PhD diss., University of Texas at Austin.

Blackburn, Simon. 1998. Ruling Passions. Oxford: Clarendon Press.

Chudnoff, Elias. 2011a. “The Nature of Intuitive Justification.” Philosophical Studies 153: 313333.

Chudnoff, Elias. 2011b. "What Intuitions Are Like." Philosophy and Phenomenological Research 82 (3): 625-654.

Cohon, Rachel. 1997. "The Common Point of View in Hume's Ethics." Philosophy and Phenomenological Research 57 (4): 827-850.

D’Arms, Justin and Jacobson, Daniel. 2003. “The Significance of Recalcitrant Emotion.” In Philosophy and the Emotions. Royal Institute of Philosophy Supplement 52, edited by Anthony Hatzimoysis, 127-145.

Döring, Sabine. 2007. "Seeing What to Do: Affective Perception and Rational Motivation." Dialectica 61 (3): 363-394.

Glüer, Kathrin. 2009. "In Defence of a Doxastic Account of Experience." Mind and Language 24 (3): 297-327.

Goldie, Peter. 2000. The Emotions. A Philosophical Exploration. Oxford: Oxford University Press.

Haidt, Jonathan 2001. "The Emotional Dog and Its Rational Tail: A Social Intuitionist Approach to Moral Judgment." Psychological Review 108: 814-834.

Horgan, Terence and Tiensen, John. 2002. "The Intentionality of Phenomenology and the Phenomenology of Intentionality." In Philosophy of Mind: Classical and Contemporary Readings, edited by David Chalmers, 520-533. New York: Oxford University Press. Huemer, Michael. 2001. Skepticism and the Veil of Perception. Lanham, MD: Rowman and Littlefield. 
Huemer, Michael. 2005. Ethical Intuitionism. Basingstoke: Palgrave Macmillan.

Hume, David 1739-40/1978. A Treatise of Human Nature. Edited by L. A. Selby-Bigge, 2nd rev. edition by P. H. Nidditch. Oxford: Clarendon Press.

Hume, David 1751/1948. Enquiry Concerning the Principles of Morals. In Hume: Moral and Political Philosophy, edited by H. D. Aiken, 171-291. New York: Hafner Press.

Kauppinen, Antti. Forthcoming a. "Intuition and Belief in Moral Motivation." In Motivational Internalism, edited by Gunnar Björnsson, Caj Strandberg, Ragnar Francén Olinder, John Eriksson, and Fredrik Björklund.

Kauppinen, Antti. Forthcoming b. "Fittingness and Idealization.” Ethics.

Kahneman, Daniel. 2011. Thinking Fast and Slow. New York: Macmillan.

Kriegel, Uriah, ed. 2013. Phenomenal Intentionality. New York: Oxford University Press.

Kriegel, Uriah. Forthcoming. "The New Feeling Theory of Emotion." European Journal of Philosophy.

Koksvik, Ole. 2011. "Intuition.” PhD diss., Australian National University.

Oddie, Graham. 2005. Value, Reality, and Desire. Oxford: Oxford University Press.

Prinz, Jesse. 2007. The Emotional Construction of Morals. New York: Oxford University Press.

Pryor, James. 2000. "The Sceptic and the Dogmatist.” Nô̂s 34 (4): 517-549.

Roberts, Robert C. 2003. Emotions. An Essay in Aid of Moral Psychology. Cambridge:

Cambridge University Press.

Roeser, Sabine. 2011. Moral Emotions and Intuitions. Basingstoke: Palgrave Macmillan.

Singer, Peter. 2005. "Ethics and Intuition.” Journal of Ethics 9: 331-352.

Sinnott-Armstrong, Walter. 2006. "Moral Intuitionism Meets Empirical Psychology.” In Metaethics After Moore, edited by Terry Horgan and Mark Timmons, 339-365. Oxford: Oxford University Press.

Smith, Adam. 1759-90/1976. The Theory of Moral Sentiments. Edited by D. D. Raphael and A. L. Macfie. Oxford: Oxford University Press.

Sosa, Ernest. 2007. A Virtue Epistemology: Apt Belief and Reflective Knowledge. New York: Oxford University Press.

Tappolet, Christine. 2011. "Values and Emotions: Neo-Sentimentalism's Prospects." In Morality and the Emotions, edited by Carla Bagnoli, 117-134. Oxford: Oxford University Press. Williamson, Timothy. 2007. The Philosophy of Philosophy. Oxford: Blackwell. 
Zagzebski, Linda. 2003. "Emotion and Moral Judgment.” Philosophy and Phenomenological Research 66 (1): 104-124. 